\title{
Atividades de Letramento Crítico em Inglês para a Educação de Jovens e Adultos
}

Patrícia Miranda Medeiros Sardinha*

\begin{abstract}
Resumo
É de extrema relevância que a escola disponibilize atividades didáticas que extrapolem âmbitos meramente conteudistas e despertem questionamentos de ordem social e recorrentes no cotidiano dos alunos. Como resultado de uma pesquisa de mestrado profissional em práticas educativas, foram desenvolvidas atividades para o público da Educação de Jovens e Adultos que utilizam a perspectiva de leitura do Letramento Crítico (LC), que é a habilidade de ler um texto de maneira ativa e reflexiva com o intuito de compreender as relações de poder, de desigualdade e de injustiça na sociedade. O presente texto tem por objetivo apresentar o caderno de atividades que foi elaborado com unidades didáticas contendo gêneros textuais multimodais (canções, charges e vídeos curtos) em Língua Inglesa, com intenção de levantar reflexões sobre o tema pluralidade cultural.

Palavras-chave: letramento crítico, educação de jovens e adultos, textos multimodais.
\end{abstract}

\section{Critical Literacy activities in English for Young and Adults Education}

Abstract

It is extremely relevant that the school provides didactic activities that go beyond mere content areas and raise questions of social and recurrent order in the students' daily lives. As a result of a professional master's research in educational practices, activities were developed for the youth and adult education audience which use the reading perspective of Critical Literacy (CL), thatis the ability to read a text in an active and reflective way in order to understand the relations of power, inequality and injustice in society. This text aims to present the activity book that was elaborated with didactic units containing multimodal texts (songs, cartoons and short videos) in English Language, with the intention of raising reflections on the theme cultural diversity.

Keywords: critical literacy, young and adults education, multimodal texts.

\section{Considerações iniciais}

A percepção da importância de inserir na escola básica a perspectiva do Letramento Crítico (LC) durante a leitura de um texto em sala de aula de Língua Inglesa deu origem à pesquisa de mestrado profissional em práticas de Educação Básica do Colégio Pedro II, no Rio de Janeiro, apresentada neste artigo. O LC tem como pressuposto a formação de cidadãos que viabilizem um mundo mais justo através da crítica aos atuais problemas políticose sociais, questionando as desigualdades e

\footnotetext{
* Professora de Língua Inglesa da Secretaria de Educação do Estado do Rio de Janeiro (SEEDUC). Email: patymime@yahoo.com.br.
} 
incentivando ações que implementem mudanças e soluções pautadas na justiça e na igualdade.

Como fruto dessa pesquisa foram elaborados um texto dissertativo intitulado " $O$ Letramento Crítico na Educação de Jovens e Adultos da rede estadual a partir de atividades com canções e outros textos multimodais em Língua Inglesa", bem como um produto educacional com atividades que foram desenvolvidas pensando no público da Educação de Jovens e Adultos (EJA), utilizando letras de canções e outros textos multimodais (cartuns, charges e vídeos curtos). Os conteúdos desses diferentes gêneros textuais serviram de base para reflexões e questionamentos com o objetivo de desenvolver o LC. O caderno de atividades Sing and Think, de acesso gratuito, está disponível em PDF no link https://www.cp2.g12.br/blog/mpcp2/files/2018/03/SARDINHA_PATRICIA_MIRANDA_MEDEI ROS_2017_produtoeducacional.pdf, para que os professores de inglês possam utilizá-lo em suas aulas, se assim o desejarem, na educação básica.

Nas linhas a seguir, o termo Letramento Crítico (LC) será definido, o público da Educação de Jovens e Adultos será apresentado, bem como o caderno de atividades que foi desenvolvido para a EJA, sob a perspectiva do LC.

\section{O Letramento Crítico (LC)}

A inserção do Letramento Crítico em atividades de leitura tem como objetivo proporcionar a compreensão de diferentes perspectivas com intuito de colaborar para o desenvolvimento de uma sociedade mais justa e igualitária, com capacidade de respeitar e celebrar a diversidade humana, seus aspectos físicos, sociais, históricos e culturais.

Sob a perspectiva do LC, as atividades de leitura são realizadas com questionamentos ao texto para destacar as intenções do autor, perceber o público a quem se destina, bem como o grupo de pessoas que não foi considerado em sua elaboração, observar as relações de poder e desigualdades subjacentes nos textos com o objetivo de trazer à tona para o leitor que a linguagem é/foi utilizada em um contexto de tempo e espaço específicos. Assim sendo,

o Letramento Crítico nos ajuda a examinar ec ombater visões estereotipadas e preconceituosas que porventura surjam nas interações em sala de aula e fora dela. É uma perspectiva educacional que tem como propósito instigar o indivíduo a repensar sua realidade, auxiliando-o a tornar-se mais consciente e autônomo para transformá-lo, se assim o decidir. O Letramento Crítico interroga as relações de poder, os discursos, ideologias e identidades estabilizados, ou seja, tidos como seguros ou inatacáveis. Proporciona meios para que o indivíduo questione sua própria visão de mundo, seu lugar nas 
relações de poder estabelecidas e as identidades que assume (CARBONIERI, 2016, p.133).

A autora Takaki elaborou alguns questionamentos que podem ser feitos após a leitura dos textos, utilizando a perspectiva do LC. Eis alguns exemplos: “(...) Em nome de quem a história está sendo contada?/ Que outras vozes/perspectivas/realidades estão faltando?/ Um texto alternativo contaria que versão da história?/A sua realidade está incluída nesse texto? Por quê? (...)" (TAKAKI, 2012, p. 976).

Importante salientar queas perguntas apresentadas por Takaki (2012) servem apenas como modelo para a utilização durante a interpretação e a reflexão das mensagens trazidas pelos diferentes gêneros textuais, outras questões podem ser feitas durante a leitura de determinado texto trabalhado em sala de aula.

Ao utilizar a perspectiva do LC em aulas de interpretação de textos, o professor pode não só desenvolver as habilidades linguísticas, nas aulas de inglês, mas também contribuir para a formação cidadã dos alunos, estimulando a capacidade crítica para questionar, por meio do diálogo, os conceitos e preconceitos presentes nos textos e nas interações sociais (SOUZA, 2014). Previne-se, com isso, a reprodução de falas e atitudes que não passaram por prévia reflexão e habilitam o aluno para um agir mais consciente em seu meio social.

Convém ressaltar que, em atividades de LC, a opinião do professor, ou de qualquer outro indivíduo que participe da interação, não deve prevalecer durante as reflexões sobre a mensagem do texto lido. O diálogo, o respeito e o exercício de escuta devem reger as relações em sala de aula. Nesse sentido, é primordial entender que os pontos fundamentais para o desenvolvimento do LC são os questionamentos, o diálogo ea compreensão. Questionar para conseguir compreender que o outro possui uma bagagem de vida que o faz pensar e agir de determinada maneira.

Com isso, os estudantes, ao lerem um texto sob essa perspectiva, são capazes de utilizar a língua, em seus diversos meios de interação, como ferramenta de ações que questionem as relações de poder e a perpetuação da injustiça social. A leitura de um texto sob a perspectiva do LC permite ao estudante analisar e questionar as relações entre diferentes pontos de vista, a relação de poder nela intrínseca, a representação de grupos sociais e as suas práticas.

Dessa forma, é importante, durante a leitura, salientar alguns aspectos presentes no texto, tais como a intencionalidade, o contexto sócio-histórico e econômico do autor 
do texto, e comparar com o momento sócio-histórico em que a leitura é realizada. Além disso, é necessário também refletir sobre as vozes/pontos de vista dos que foram esquecidos ou ignorados na elaboração do texto.

Para um maior aprofundamento da perspectiva de leitura do LC, sugere-se a leitura do artigo "Letramento Crítico: uma abordagem crítico-social dos textos" (SARDINHA, 2018) que conceitua o LC e aponta as suas contribuições para o meio social. Esse texto também propõe o ensino da gramática associada ao LC, bem como estimula a utilização dessa perspectiva de leitura na escola.

\section{A Educação de Jovens e Adultos (EJA)}

A Educação de Jovens e Adultos é uma modalidade da educação básica voltada para alunos com mais de 15 anos (para estudantes do Ensino Fundamental) e para os maiores de 18 anos (para os que desejam cursar o Ensino Médio) (BRASIL, 1996). Sendo assim, a sala de aula de uma turma de EJA é composta por jovens, adultos e, por vezes, idosos, que interagem em um mesmo ambiente, com perspectivas e objetivos diferentes ao procurar a escola.

Usualmente, os alunos da EJA são oriundos das classes populares que, por diferentes motivos, se distanciaram do processo escolar, ou são alunos jovens, repetentes do ensino diurno, que procuram essa modalidade de ensino para adiantar os estudos. De modo geral, todos, apesar das dificuldades que encontram para manter a rotina de estudo, são indivíduos que possuem perspectivas de futuro profissional, mas que investem no presente e acreditam que o processo de escolarização lhes proporcionará um trabalho mais estável ou promissor. Ainda existem aqueles que já são aposentados e/ou já têm filhos criados, mas retornam à escola para adquirir o diploma como realização pessoal, sede pelo conhecimento e busca de interação entre indivíduos que é proporcionada pela escola. Segundo Arroyo,

Essas diferenças podem ser uma riqueza para o fazer educativo. Quando os interlocutores falam de coisas diferentes, o diálogo é possível. Quando só os mestres têm o que falar não passa de um monólogo. Os jovens e adultos carregam as condições de pensar sua educação como diálogo. Se toda educação exige uma deferência pelos interlocutores, mestres e alunos(as), quando esses interlocutores são jovens e adultos carregados de tensas vivências, essa deferência deverá ter um significado educativo especial (ARROYO, 2007, p. 35). 
Os motivos desses estudantes procurarem a EJA são muitos, mas o que todos buscam em comum é a melhoria de suas condições sociais. Paulo Freire $(1987 ; 1997)$, em seus escritos, incentiva os professores a considerar os sujeitos da EJA como indivíduos de cultura e de leitura de mundo que procuram a escola não para obter uma educação bancária ou compensatória, mas com perspectiva de emancipação e aprimoramento.

Pensando nisso, os professores precisam levar em consideração as características desse público tão peculiar no fazer pedagógico em sala de aula de Língua Inglesa,

(...) Lugar esse que deve ser regado a diálogo. Lugar esse cujo objetivo principal é a emersão de memórias e de saberes dos estudantes. Lugar esse em que o currículo deve ser flexível e não engessado ou pré-definido, construído considerando as necessidades desse público tão híbrido e a bagagem cultural dos/as educando/as (MEDEIROS; FONTOURA, 2017, p. 87).

Uma vez que, ao retornar para a escola, o aluno da EJA busca aprendizagens significativas para serem colocadas em prática em seu viver cotidiano que o permita "se desenvolver e constituir conhecimentos, habilidades, competências e valores que transcendam os espaços formais da escolaridade e conduzam à realização de si e ao reconhecimento do outro como sujeito" (BRASIL, Parecer CNE/ CEB nº11/2000, p.12). Ciente disso, a EJA não pode ser pensada como recuperação de tempo perdido, mas, sim, em uma ação educativa que colabore para que os alunos possam adquirir conhecimentos que contribuam para a sua formação enquanto agentes sociais.

\section{Caderno de Atividades elaborado sob a perspectiva do LC para a EJA}

O desenvolvimento da pesquisa-ação, realizada durante o mestrado profissional, de caráter qualitativo (GOLDENBERG, 2004; THIOLLENT, 2009), contribuiu para a elaboração do produto educacional intitulado Sing and Think (SARDINHA, 2017), disponível em pdf de acesso gratuito por site de busca. O caderno de atividades visa ao desenvolvimento do LC dos estudantes da EJA e, dentre outros objetivos, possui o intuito de fazê-los refletir acerca das diversidades em um mundo caracterizado por constantes transformações sociais, econômicas, políticas e culturais.

O campo de estudo dessa pesquisa-ação foi a escola e seus resultados vieram a partir da prática de sala de aula, por meio de compreensões e do diálogo sobre práticas 
sociais advindas das unidades didáticas aplicadas, que serviram como ferramenta de intervenção sobre a amostra selecionada: um grupo de alunos do $9^{\circ}$. ano do Ensino Fundamental e também do Ensino Médio, do CEJA (Centro de Educação de Jovens e Adultos), localizado na cidade deNiterói, RJ. No CEJA, o ensino é semipresencial, os alunos estudam por apostilas em casa e voltam à escola para tirar dúvidas com os professores bem como para fazer as provas. As oficinas são oferecidas pelos professores para, além da socialização, promover palestras de conscientização sobre assuntos diversos, como câncer de mama, por exemplo; sanar dúvidas de conteúdos que os alunos apresentam maior dificuldade etc.

As atividades do caderno Sing and Think foram aplicadas em forma de oficina, com duração de duas (2) horas, em horários pré-agendados, com inscrição prévia dos alunos interessados. Dos vinte e cinco (25) alunos inscritos, apenas oito (8) foram considerados para a análise dos dados da pesquisa e participaram do Grupo Focal, pois foram esses que compareceram a todos os quatro (4) encontros realizados, os demais não puderam comparecer a todas as oficinas disponibilizadas por motivos diversos.

Cabe informar que Grupo Focal (GF) é uma técnica de entrevista coletiva que se caracteriza pela participação de pessoas que compõem um grupo formado por características comuns que se reúnem, convocadas por um moderador. O objetivo do GF é trocar experiências, ideias e opiniões entre os participantes e fazer emergir seus pontos de vista, permitindo, assim, um maior aprofundamento dos objetivos da pesquisa por meio da interação entre os participantes a partir das perguntas realizadas pelo moderador. No caso desta pesquisa, a professora pesquisadora foi a moderadora e os estudantes do CEJA, sujeitos da amostra selecionada, integraram o GF (SARDINHA, 2017a).

O grupo que compôs a amostra selecionada representa uma parcela ínfima dos alunos que frequentam a EJA, porém a aplicação do produto educacional possibilitou verificar se as unidades elaboradas seriam úteis para o desenvolvimento do LC dos alunos dessa modalidade de ensino. Verificou-se ao final das oficinas que os oito (8) integrantes da amostra selecionada conseguiram perceber vozes e grupos excluídos durante a leitura dos textos; foram capazes de problematizar as relações de poder existentes na sociedade; perceberam que o preconceito e a discriminação são uma 
realidade local, mas também global e que as ações individuais de respeito ao próximo podem surtir efeitos benéficos nos diferentes relacionamentos.

Importante destacar que, das oito (8) unidades disponíveis no produto educacional, quatro (4) unidades didáticas foram aplicadas, durante a pesquisa-ação realizada, e serviram como instrumento de intervenção sobre a amostra selecionada, incentivando o conhecimento, a reflexão e os questionamentos sobre as mensagens trazidas pelos textos multimodais disponibilizados. Tal intervenção permitiu observar a importância do diálogo e do exercício de escuta da perspectiva do outro que podem levar os indivíduos a compreender as relações de poder e de injustiça, presentes nos relacionamentos.

Convém salientar que, na elaboração do caderno de atividades, foi levada em consideração a dimensão sócio-histórica da linguagem e a sua utilização nos diversos ambientes de interação por meio dos gêneros textuais. $O$ enfoque sociointeracional pressupõe que a pessoa do discurso, aquela que produz o texto (falado ou escrito), precisa considerar aqueles a quem se dirigem nas relações sociais, considerando também o posicionamento cultural, histórico e social dos interlocutores. Para isso, o estudante precisa conhecer a estrutura e a função dos gêneros textuais para a aplicação nas relações sociais, além de levar em consideração o processo sócio-histórico-cultural do momento em que o texto foi produzido.

O produto educacional Sing and Think foi desenvolvido para ser utilizado pelo professor de Língua Inglesa da EJA e inclui: apresentação do material, com o objetivo de informar o professor sobre a temática das unidades e sobre a perspectiva de leitura dos textos, que é baseada no LC; breves considerações sobre o trabalho com o texto, sob a perspectiva do LC; orientações para o professor trabalhar as seções que compõem as unidades didáticas; sugestão de apresentação dos gêneros textuais; unidades fotocopiáveis para a distribuição entre os alunos, com tarefas para serem executadas individualmente, em duplas e/ou em grupo; informações extras sobre as canções, seus contextos históricos de produção, compositores, cantores/bandas e respostas dos exercícios; sugestões de aplicativos e sites para estudo autônomo do inglês, além de recomendações de filmes relacionados ao tema pluralidade cultural; sugestões de leitura (artigos e livros) para o professor. 
As unidades didáticas elaboradas abordam o tema pluralidade cultural, mais especificamente o preconceito racial, as diversidades religiosa e cultural e as diferenças de atuação social entre os gêneros masculino e feminino, assuntos que apareceram nas atividades produzidas para que os estudantes possam refletir e desenvolver a compreensão mútua, a tolerância, a fraternidade e a paz para participação plena como cidadãos ativos e conscientes.

Além disso, percebeu-se a relevância do trabalho com os gêneros textuais multimodais: canção, cartum, charge e vídeo curto, uma vez que as imagens presentes em tais textos auxiliam na compreensão da mensagem do texto; a música (o som atrelado à letra da canção) proporciona um ambiente favorável e estimulante para aprendizagem da língua; a mensagem imbuída nesses textos traz subsídios para reflexões e questionamentos sobre as relações humanas em termos locais e globais. $\mathrm{O}$ aluno, com isso, é incentivado a "ler o mundo" com pensamento crítico, analisando o contexto de produção e de leitura dos textos.

Outro ponto que é necessário sublinhar é que, nos textos multimodais, a combinação de diversos recursos semióticos (escrita, som, imagem, gestos, movimentos, expressões faciais, entre outros) são utilizados para construção de significados em uma situação comunicativa. Santos (2008) ressalta a relevância de "expandir a abordagem dos textos multimodais, sua significação dentro de um contexto social e a necessidade de ampliar a leitura de textos que extrapolam o modo semiótico verbal" (SANTOS, 2008, p. 84). A presença do elemento verbal relacionado ao não verbal em um texto pode facilitar a sua compreensão quando no estudo do gênero textual em língua estrangeira.

A utilização de textos multimodais em aulas de Língua Inglesa abre portas para que temas como preconceito racial e religioso, por exemplo, sejam refletidos. Dessa forma, a leitura desses textos, sob a perspectiva do LC, torna-se uma possibilidade de alcançar a igualdade de gênero, permitir que meninas e mulheres participem de maneira plena na política, em sociedade e na economia como cidadãs de direitos. Além disso, por meio de variados textos em inglês, um debate amplo sobre a diversidade cultural pode ser trazido à tona para que atos de segregação, discriminação e injustiça social não mais ocorram, ao menos no entorno dos alunos que tiveram acesso às reflexões acerca da pluralidade cultural disponibilizadas pelas unidades didáticas. 
Desse modo, o ensino-aprendizagem da língua estrangeira vai além da aquisição das habilidades comunicativas, permitindo ao estudante conviver com as diferenças, dando subsídios para que os estudantes possam valorizar a coletividade em detrimento da individualidade, praticar o exercício de escuta, aprender a propor idéias e não as impor, administrar conflitos por meio do diálogo, buscar a unidade em meio à diversidade, focar em ações de empatia, de solidariedade e de cooperação.

Cada unidade do caderno de atividades procura integrar as quatro habilidades da língua (ler, escrever, ouvir e falar), porém o nível de proficiência da turma como um todo precisa ser respeitado, fazendo possíveis adequações quanto à realidade da turma. De modo geral, no ensino da Língua Inglesa,

As atividades propostas para o ensino de línguas têm sido tradicionalmente classificadas em quatro grandes áreas: (1) fala, (2) escuta, (3) leitura e (4) escrita. Os materiais podem ser preparados para cada uma dessas habilidades, em separado, ou de modo integrado, incluindo duas ou mais habilidades (LEFFA, 2007, p. 28).

As unidades do produto educacional elaborado permitem o trabalho com escuta, leitura e escrita em Língua Inglesa, como pode ser observado na Unidade 1 (figuras 1 e 2), que é parte integrante do caderno de atividades Sing and think. Cabe ao professor, ao utilizar qualquer uma das unidades didáticas, conhecer previamente o grupo de alunos para decidir se as interações orais serão feitas em língua materna ou em inglês, pois o objetivo é que haja a efetiva participação de todos nas reflexões, para que, porventura, a falta de vocabulário da Língua Inglesa não impeça a expressão de ideias e compreensões sobre os textos. 


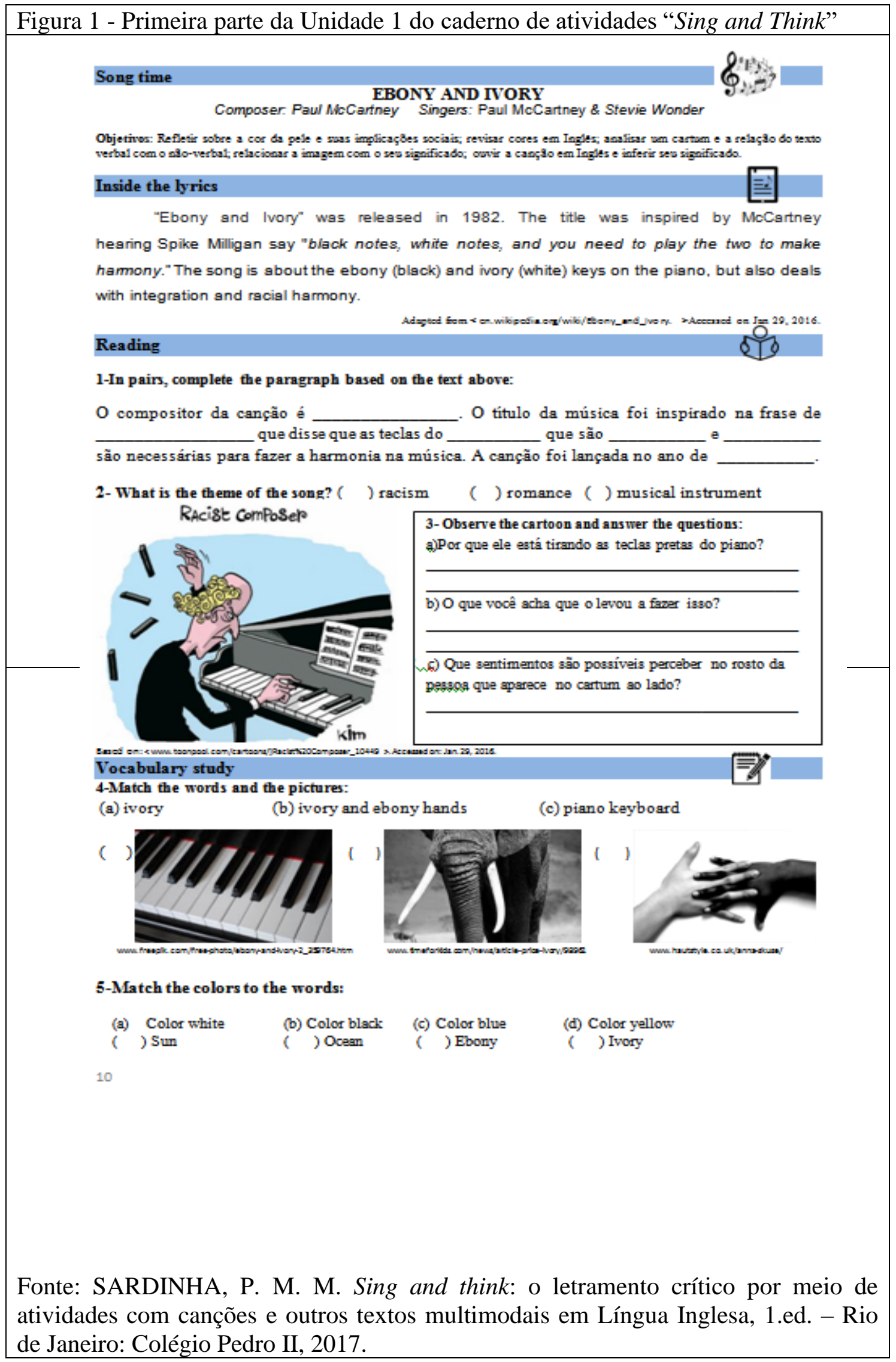


Figura 2 - Continuação da Unidade 1 do caderno de atividades "Sing and think"

Listening

6-Listen to the song and circle the correct word:

Ebony And Ivory Composer. Paul McCartney Singers: Paul McCartney \& Stevie Wonder

Ebony and ivory live together in perfect (harmony - tendency - majesty)

Side by side on my piano keyboard, oh Lord, why don't (she - we - he)?

We all know that people are the same wherever we (do-go-to)

There is good and bad in everyone,

We learn to live, we learn to (learn - love - give)

Each other what we need to survive together alive.

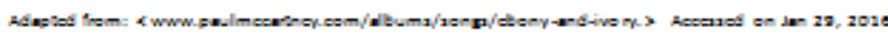

7-Complete the translation:

Ebano e marfim vivem juntos em perfeita

Lado a lado no meu teclado do oh Senhor, por que nós não?

Todos sabemos que as pessoas são iguais aondequer que vamos

Existe __ mal em todos,

Aprendemos a viver, aprendemos a dar

Uns aos outros o que precisamos para sobrevivermos juntos.

8- Watch the video: "Ebony \& Ivory - Stevie Wonder \& Sir Paul McCartney"

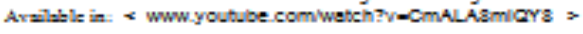

\section{Talking about the song}

1-As teclas pretas e brancas do piano juntas fazem lindas canções. Por que nós, seres humanos, não conseguimos viver juntos em harmonia?

2-Na segunda estrofe, o autor da canção afirma que as pessoas são iguais. Você concorda com isso?

3-Nessa canção, duas cores de pele foram representadas. Quais foram omitidas?

4-Você acha que essa canção, escrita em 1982, faz sentido hoje em dia? Por quê?

\section{Task}

Produzir um cartaz coletivo com o seguinte titulo: What is my skin color?

Cada aluno escreve seu nome e cola um lápis de cor ou giz de cera que representa seu tom de pele.

Exemplo:

I am

My skin color is

$=0$ -

Fonte: SARDINHA, P. M. M. Sing and think: o letramento crítico por meio de atividades com canções e outros textos multimodais em Língua Inglesa, 1.ed. - Rio de Janeiro: Colégio Pedro II, 2017. 
Todas as unidades reunidas no caderno de atividades foram desenvolvidas pensando no estudante da EJA, no seu processo de aprendizagem da Língua Inglesa, levando em consideração a sua bagagem cultural e as suas experiências de vida. Almeja-se que esse estudante assuma um papel ativo em sua formação educacional para ser um cidadão consciente e atuante nos diversos ambientes em que interage com ações que prezem pelo respeito ao próximo. Para isso, foram utilizados textos multimodais, com propósitos, composição (lingüística e ideológica) e suporte (papel, tela digital, imagens, som) diferenciados, cada qual com suas especificidades e implicações na vida diária dos estudantes.

Como vimos, cada unidade didática é dividida em seções e cada uma das seções está relacionada e descrita no caderno de atividades, com sugestões de como o professor pode trabalhá-las com os estudantes. Convém ressaltar que as respostas dos exercícios são disponibilizadas logo após cada unidade.

Vale salientar que as atividades nas seções "Listening e Reading" contemplam a utilização de tradução para o português. Esta é uma ferramenta didática muito útil para o trabalho com turmas da EJA, que são formadas por alunos em diferentes níveis de conhecimento do inglês, pois proporciona o desenvolvimento de habilidades linguísticas e melhor compreensão da língua estrangeira. Segundo Bittencourt e Tecchio (2011), a tradução é um recurso para a compreensão do funcionamento da língua e permite a comparação entre os códigos, facilitando o aprendizado da Língua Inglesa e também reforçando o da língua materna.

Além disso, na chave de respostas para o professor, do caderno de atividades Sing and think, na seção "Talking about the song”, é sugerido que não existem respostas prontas, mas que todos os estudantes podem expressar suas opiniões buscando ações que não expressem atitudes individualistas, mas que privilegiem a coletividade, a justiça e o diálogo para resolução de conflitos. Uma vez que, diante da diversidade de contextos, não existe uma única resposta, pois cada sala de aula tem sua característica própria, sendo formada por indivíduos com uma história de vida e de identidade construídas com experiências ímpares. Nesse sentido, o material elaborado estimula práticas de leitura com finalidade de transformar o estudante em um cidadão consciente, reflexivo e questionador, dentro e fora da escola, tendo o texto em inglês como gerador dessas reflexões. 
Importante salientar também que o docente precisa levar o estudante a refletir sobre o posicionamento sócio-histórico atual da leitura e compará-lo com o momento sócio-histórico da elaboração do texto para compreender as relações de poder e, com isso, alterar o círculo vicioso de ações de desigualdade e exclusão, observadas em sociedade, para ações de justiça e equidade, ao menos nos relacionamentos mais próximos, na realidade local.

Durante os encontros de aplicação das atividades, todos os integrantes da amostra selecionada tiveram a oportunidade de expressar suas opiniões e contar as suas experiências de vida em relação ao tema proposto em cada unidade. Com a realização das oficinas, foi possível observar como esse momento de troca foi importante para percepção da história de vida do outro, proporcionando a tomada de consciência pela compreensão e pelo respeito ao próximo que devem ser um exercício diário de consideração do espaço do outro. Além disso, o exercício de escuta, proporcionado nos quatro (4) encontros da oficina, evidenciou que o respeito é o ponto de partida para as interações em qualquer tipo de relacionamento, seja familiar, seja conjugal, com colegas de trabalho, com vizinhos, com desconhecidos, com os seres humanos em geral. As experiências de aprendizagem mediadas pelo diálogo proporcionam compreensões da realidade e estabelecem subsídios para intervenção na realidade vivenciada. Cientes de que o diálogo deve ser o instrumento utilizado para a resolução de conflitos e que procurar compreender a história de vida do outro (os caminhos que foram trilhados para chegar aonde se chegou e para ser o que se é hoje) pode ser a chave para relacionamentos mais harmoniosos.

A título de exemplificação, na entrevista, ao final dos encontros da oficina, a pesquisadora perguntou como foi a experiência de ouvir as respostas e opiniões dos demais participantes sobre o tema de cada unidade. As respostas a essa pergunta estão transcritas a seguir:

Aluno 8: Para mim foi conhecimento. Porque eu tenho a minha opinião e cada um tem a sua. Então, o que eu falei agregou para ela e o que elas falaram agregou em mim também.

Aluno 6: Isso mesmo que eu queria falar, que a gente aprende com cada um, cada um fala uma coisa, ela fala outra e ele fala, né? Cada um tem a sua opinião e cada opinião vai somando. Então, é válida e a gente, né, não vai discutir, mas a gente debate, né? E acaba que cada um vai aprendendo um com o outro e eu acho isso muito importante.

Aluno 3: Eu concordo com ela (referindo-se ao aluno 6). 
Aluno 5: Foi bom, né. Agora falar eu não sei.

Aluno 2: Eu acho que foi bom para aprendizado e o pouco que cada um falou foi bom para gente pensar o que a gente disse e aprender mais para ir levar para vida, então.

Aluno 5: Foi bom quanto à informação, né? Que cada um tem uma opinião, e aí, chegamos cada um a uma conclusão e aí vamos levando.

Destaca-se, com isso, o papel fundamental da escola como reprodutora de significados. Ela permite que os estudantes tenham acesso ao saber escolar advindo dos livros, das atividades didáticas e dos professores, permitindo, também, a comparação entre a realidade vivida e as ocorrências ao longo da história para que atitudes de violência e de injustiça não sejam reproduzidas. Diante disso, a concepção de ensino da Língua Inglesa vem passando por transformações no sentido de desempenhar um papel relevante na formação do aluno-cidadão atuante na sociedade em que está inserido, por meio de atividades que levem em consideração o contexto desse aluno e a sua bagagem cultural.

Acerca disso, os gêneros multimodais utilizados no caderno de atividades elaborado são textos carregados de significados, com enorme potencial para produzir conhecimento, fazer refletir, questionar as ações de injustiça e proporcionar ações de respeito ao próximo, suscitando reflexões sobre a pluralidade cultural que vivenciamos no cotidiano: diversidade religiosa, étnico-racial e diferenças de atuação social entre os gêneros.

\section{Considerações Finais}

O ensino-aprendizagem de Língua Inglesa precisa redimensionar seus objetivos diante da prática pedagógica com os alunos da EJA: além do ensino de habilidades lingüísticas e do estudo dos aspectos estruturais da língua, as aulas de Língua Inglesa precisam proporcionar um ambiente de reflexões e de questionamentos sobre práticas sociais e culturais, locais e globais, abordadas pelos textos trabalhados, ressaltando que a pluralidade cultural que perpassa as obras humanas como um todo deve ser reconhecida e contextualizada para melhor compreensão e interpretação do texto. Ressalta-se, portanto, a importância de práticas de ensino de inglês que se preocupam com a formação do cidadão e de seu papel na sociedade. 
Assim, lançando mão de subsídios teóricos do LC, foram elaboradas atividades com uso de canções em Língua Inglesa, bem como de outros textos multimodais, para despertar reflexões e questionamentos que permitem aos estudantes terem acesso não só à estrutura da língua por meio dos textos disponibilizados, mas também terem condição de perceber que os preconceitos observados aqui no Brasil ocorrem também em outros países. Pois, apesar de toda evolução tecnológica do século XXI, o ser humano ainda sofre com atitudes racistas e discriminações no início dos tempos (conforme observado no desenrolar da história humana). Por esse motivo, a escola possui papel fundamental de inibir ações de segregação e de violência. Nesse sentido, a utilização do LC como perspectiva de leitura dos variados textos a que os estudantes têm acesso proporciona o questionamento das mensagens por eles trazidas e a comparação com a realidade vivenciada para um agir, considerando a justiça e a igualdade entre os indivíduos.

Com isso, as unidades didáticas foram elaboradas com o intuito de contemplar interações e diálogos acerca do tema gerador das atividades, que é a "pluralidade cultural" (mais especificamente o preconceito racial, a diversidade religiosa e cultural e diferenças de atuação social entre os gêneros masculino e feminino). Dessa forma, o compartilhar de ideias sobre os assuntos trazidos pelas letras das canções, cartuns e video clipes proporcionaram, na amostra selecionada, reflexões e a escuta do ponto de vista e da experiência do outro.

Uma das possíveis limitações do produto educacional elaborado pode estar na sua utilização por outros docentes, pois o resultado positivo desta pesquisa-ação esteve atrelado à prática da própria autora das unidades, que tinha os objetivos definidos e conhecia a perspectiva de leitura do LC para a utilização das unidades junto à amostra selecionada. Os professores que optarem por utilizar tais unidades podem não obter o mesmo resultado, por diferentes motivos: utilizar somente parte da unidade; decidir não incentivar o diálogo e reflexões a partir das mensagens dos textos da unidade, ou utilizála com um público que não seja o da EJA. É evidente que quem produz a unidade didática domina melhor os seus objetivos, e a probabilidade de alcançá-los aumenta. Contudo, isso não impossibilita que outros professores utilizem as unidades e tenham as suas expectativas alcançadas.

Enfim, as atividades com textos multimodais (letra de canção, cartum, charge, vídeo curto e vídeo clipe), utilizando o tema Pluralidade Cultural, disponíveis no 
produto educacional Sing and Think, pretendem contribuir de alguma forma na promoção do desenvolvimento do LC nos alunos da EJA, almejando práticas sociais mais justas e igualitárias. Espera-se que o material desenvolvido seja útil para a prática pedagógica de outros professores e que permita o desenvolvimento da consciência crítica dos estudantes-trabalhadores que possuem experiências de vida que podem e devem ser compartilhadas a partir da temática proposta em cada unidade didática, contribuindo para a formação desses cidadãos e para a construção de um país que respeita as suas diversidades.

\section{Referências}

ARROYO, Miguel. Educação de Jovens e Adultos: um campo de direitos e de responsabilidade pública. In: GIOVANETTI, Maria Amélia, GOMES, Nilma Lino e SOARES, Leôncio (Orgs.). Diálogos na Educação de Jovens e Adultos. 2 ed. Belo Horizonte: Autêntica, p. 19-50, 2007.

BITTENCOURT, Marcelina; TECCHIO, Iliana. A Tradução no Ensino-Aprendizagem de Línguas Estrangeiras. In: Revista Magistro - ISSN: 2178-7956. Revista do Programa de Pós-Graduação em Letrase Ciências Humanas - UNIGRANRIO. Vol. 2 Num.1. p. 152-165. 2011.

BRASIL. Lei de Diretrizes e Bases da Educação Nacional. Brasília: MEC/SEF, 1996.

Parecer CNE/CEB $n^{\circ} 11 / 2000$, de 07 de junho de 2000a. Dispõe sobre as Diretrizes Curriculares Nacionais para a Educação de Jovens e Adultos.

CARBONIERI, Divanize. Descolonizando o Ensino de Literaturas de Língua Inglesa. In: JESUS, Dánie Marcelode. CARBONIERI, Divanize (org). Práticasde Multiletramentos e Letramento Crítico: outros sentidos para a sala de aula de línguas. Coleção: Novas Perspectivas em Linguística Aplicada. Vol. 47. Campinas, SP: Pontes Editores, 2016.

FREIRE, Paulo. Pedagogia da autonomia: saberes necessários à prática docente. São Paulo: Paz e Terra, 1997.

Pedagogia do oprimido. São Paulo; Paz e Terra, 1987.

GOLDENBERG, Mirian. A arte de pesquisar. Como fazer pesquisa qualitativa em ciências sociais. Rio de Janeiro: Record, 2004.

LEFFA, V. J. Como produzir materiais para o ensino de línguas. In: LEFFAV. J. (org.) Produção de materiais de ensino: teoria e prática. 2. ed. rev.- Pelotas: Educat, p.15-41, 2007. 
MEDEIROS, Letícia Miranda; FONTOURA, Helena do Amaral. O desafio de ensinar língua inglesa na Educação de Jovens e Adultos. In: Revista Educação Popular, Uberlândia, v. 16, n. 1, p. 82-91, jan./abril. 2017.

SANTOS, Záira Bomfante dos. A construção de uma leitura multimodal em Língua estrangeira. In: Revista Educação em Destaque. Juiz de Fora, v. 1, n. 2, p. 75-86, $2^{\circ}$ sem. 2008.

SARDINHA, P. M. M. O Letramento crítico na Educação de Jovens e Adultos da rede estadual a partir de atividades com canções e outros textos multimodais em Língua Inglesa. Dissertação (Mestrado Profissional em Práticas de Educação Básica). Colégio Pedro II. Rio de Janeiro, 2017.

Sing and think: o letramento crítico por meio de atividades com canções e outros textos multimodais em Língua Inglesa, 1. ed. - Rio de Janeiro: Colégio Pedro II, 2017.

Letramento Crítico: uma abordagem crítico-social dos textos. In: Revista Linguagens \& Cidadania v. 20, jan./dez., 2018.

SOUZA, Gasperim Ramalho de. Novos significados para o ensino e aprendizagem de inglês: O letramento crítico em uma turma de aceleração. Dissertação de mestrado. (Linguística Aplicada). UFMG. Faculdade de Letras. 2014.

TAKAKI, Nara Hiroko. Contribuições de teorias recentes de letramentos críticos para inglês instrumental. In: RBLA, Belo Horizonte, v. 12, n. 4, p. 971-996, 2012.

THIOLLENT, M. Metodologia da pesquisa-ação. São Paulo: Cortez, 2009.

Recebido em: 31 jan. 2019.

Aceito em: 23 abr. 2019. 